\title{
Acute corneal erosion from the use of anti-misting agent in swimming goggles
}

\author{
S J Doyle
}

The number of ways that the human cornea can be injured by physical or chemical agents is extremely variable and sometimes bizarre. ${ }^{12} \mathrm{We}$ describe here one such occurrence.

\section{Case report}

A 63-year-old man, a keen long distance swimmer, presented in the casualty department just after completing a 2 hour swim in Bala lake in Wales. When he had finished the swim and removed his goggles, he found that his left vision was very blurred, and the eye painful and gritty. On examination, later the same day, he was found to have a total epithelial erosion of his left cornea. The right eye was completely normal. The corneal epithelium healed uneventfully over 48 hours although he had occasional grittiness during the next few weeks.

Before his swim he had sprayed the inside of his goggles with 'Calotherm', a widely available anti-misting agent (Calotherm International, Beckenham, Kent). This is an aqueous solution containing less than $15 \%$ ethoxylated long chain primary alcohols and less than $5 \%$ isopropanol in a pump action, air-propelled container. As far as he remembers, he followed the manufacturer's instructions by allowing the agent to evaporate to dryness. However, the rims of his goggles were composed of an absorbent sponge material and it is quite likely that he sprayed them as well. He was keen to use plenty of spray on the basis that 'more of it would work better'. He also sprayed more agent onto the left lens, on starting the pump action of the spray, than the right. The anti-misting agent was recommended to him by a friend and he had only used it a few times. He had experienced a similar, less severe episode, also after the use of 'Calotherm', a few months previously following an hour long swim off Lanzarote. This was diagnosed as conjunctivitis by a local emergency doctor and treated with antibiotic drops. He has no previous history of eye trauma and there is no corneal dystrophy.

\section{Comment}

Although the patient is, understandably, not willing to undergo a controlled trial to elucidate the problem further, we are fairly certain that his unusual erosion was caused by alcohol fumes evaporated from his goggles. In a confined space and over a long period of time they could clearly cause epithelial damage as described.

The commonest cause of alcohol damage to the cornea is that due to imperfectly cleaned tonometer heads. ${ }^{3} \mathrm{~A}$ similar problem also occurs with hydrogen peroxide. ${ }^{4}$ Aerosol damage is usually by direct accidental spraying ${ }^{5}$ but can also be malicious. ${ }^{6}$ In our case the propellant was compressed air by the action of the hand pump and any ocular toxicity must be from the agent alone rather than the propellant which, in other aerosols, can be butane or fluorocarbon derivatives. Our patient has now gone back to the old remedy for demisting - spitting on the inside of the goggles before swimming.

We advise, therefore, that swimmers or other people using enclosed goggles for prolonged periods (for example, welders) and using 'Calotherm' or similar anti-misting agents, should make sure that they are dry in all elements before use. People should also avoid using an excessive amount of the agent.

1 DeRespinis PA, Prohman LP. Microwave popcorn - ocular injury caused by steam. [Letter] $N$ Engl f Med 1990; 323: 1212.

2 Chang PC, Soong HK, Barnett JM. Corneal penetration by tarantula hairs. [Letter] $\mathrm{Br} \mathcal{F}$ Ophthalmol 1991; 75: 253-4.

3 Soukiasian SH, Asdourian GK, Weiss JS, Kachadoorian HA. A complication from alcohol-swabbed tonometer tips. A complication from alcohol-sw

Hospital, Oxford Road Manchester M13 6WH S J Doyle Correspondence to: S J Doyle.

Accepted for publication 24 November 1993
4 Pobrebniak AE, Sugar A. Corneal toxicity from hydrogen peroxide soaked tonometer tips. [Case report] Arch Ophthalmol 1988; 106: 1505.

5 Ben-Nissan D, Savir H. Ocular injury by artificial snow spray. Harefauh 1990; 119: 370.

6 Klyve P. Tear gas and eye injuries. Tidsskr Nor Laegeforen 1992; 